\title{
Apnea of Prematurity: An Update
}

\author{
Alex Gileles-Hillel ${ }^{1} \quad$ Ira Erlichman ${ }^{2}$ Joel Reiter ${ }^{1}$ \\ 1 Pediatric Pulmonology, Sleep and CF Unit, Department of Pediatrics, \\ Hadassah-Hebrew University Medical Center \& Faculty of Medicine, \\ Jerusalem, Israel \\ 2 Neonatology Unit, Department of Pediatrics, Hadassah-Hebrew \\ University Medical Center \& Faculty of Medicine, Jerusalem, Israel \\ J Child Sci 2019;9:e50-e58.
}

Address for correspondence Alex Gileles-Hillel, MD, Pediatric Pulmonology, Sleep and CF Unit, Department of Pediatrics, HadassahHebrew University Medical Center, Jerusalem, Israel

(e-mail: alexgi@hadassah.org.il).

\begin{abstract}
Keywords

- apnea

- hypoxia

- prematurity

- caffeine

Apnea of prematurity (AOP) affects the majority of infants born prematurely, before 34 weeks of gestational age. AOP is a common diagnosis in the neonatal intensive care unit and one of significant clinical importance, both immediate and long term, as it is associated with reduced survival and poorer respiratory and neurodevelopmental outcomes. In this review, we provide an up-to-date summary of recent advances in the understanding of the pathophysiology of AOP, as well as the clinical questions relevant to physicians and staff treating infants with AOP. Finally, we discuss monitoring and discharge decisions, as these are areas of significant uncertainty.
\end{abstract}

\section{Introduction}

Preterm birth is defined by the World Health Organization as delivery before 37 completed weeks of gestation, with extreme prematurity defined as birth occurring at less than 28 weeks of gestational age (WGA), very preterm birth occurring between 28 and $32 \mathrm{wGA}$, and moderate-to-late preterm birth occurring from 32 through 36 wGA. ${ }^{1}$ Each year, 15 million infants are born prematurely, comprising $11 \%$ of the total children born worldwide. Prematurity is the leading cause of mortality under the age of 5 years, and its incidence is on the rise, despite efforts to reduce premature birth and its complications. Long-term morbidity, as a result of prematurity, such as the increased risk of cerebral palsy, learning disabilities, and cardiovascular and respiratory disorders, present significant challenges to public health and often lead to chronic disease in adulthood. ${ }^{1-4}$

Apnea of prematurity (AOP) is defined by recurrent significant idiopathic apnea (cessation of breathing $>20$ seconds) or respiratory pauses of shorter duration in the presence of bradycardia ( $<100$ beats per minute) and/or oxygen desaturations $(<90 \%){ }^{5}$ Apnea can be central with cessation of respiratory effort along with cessation of airflow, obstructive, with continuous respiratory effort along with absence of airflow, or mixed, consisting of both central and obstructive components received

December 29, 2018

accepted after revision

January 3, 2019
Issue Theme Sleep Disorders in Children; Guest Editors: David Gozal, MD, MBA, PhD (Hon), and Leila Kheirandish-Gozal, MD, MSc. during the same apneic event. As discussed below, several mechanisms predispose premature infants to apnea. Apnea does not describe a single entity per se, and additional etiologies, such as sepsis, anemia, necrotizing enterocolitis (NEC), hypothyroidism, or intraventricular hemorrhage, should be pursued when a premature infant develops apnea, before assuming that the idiopathic form of AOP is the correct diagnosis. AOP affects the vast majority of infants born $<28$ wGA, with decreasing rates as the gestational age at birth increases. However, AOP prevalence is present in as many as $20 \%$ of those born as late as 34 wGA. ${ }^{6,7}$

\section{Pathophysiology}

Several mechanisms contributing to the development of AOP have been described:

\section{Control of Breathing}

Breathing control immaturity in the prematurely born infant is the most established mechanism, leading to unstable breathing patterns and apneas. Breathing control undergoes significant maturational processes in utero. During fetal life, breathing is not continuous, is characterized by brief pauses, and becomes continuous at term to maintain adequate 
ventilation and oxygenation after birth. Rhythmic breath generating neurons are located in the pre-Bötzinger area of the brain stem and are responsible for the continuous output of efferent signals to the respiratory muscles. ${ }^{8}$ The development of this intricate network requires synaptogenesis and myelination in the nucleus tractus solitarius neurons, a process that nears maturation only at term, thus explaining the unstable breathing patterns seen earlier in life. One example for evidence of incomplete myelination playing a role in AOP pathogenesis comes from a study that compared auditory brain-evoked responses in premature infants with and without AOP. ${ }^{9}$ The evoked responses to auditory stimuli in the apneic group were delayed, as compared with nonapneic infants, and the shortening of auditory response latencies coincided with reductions in the number of apneas, implicating neuronal conduction in the brain stem as the mechanism responsible for apnea. Furthermore, immaturity is not limited to the breathing control centers. Immaturity of the brain stem chemosensitive neuronal network that responds to fluctuations in blood $\mathrm{CO}_{2}$ has a profound effect on the respiratory response and tendency for apnea in premature infants. ${ }^{10}$

Another mechanism proposed to explain AOP is periodic breathing, which is frequent in term neonates and even more so in premature ones. This unstable breathing pattern is partly explained by increased sensitivity of peripheral chemoreceptors to hypoxia, fostering increased ventilatory responses during the early phase of hypoxia, resulting in hypocapnia, and ultimately leading to depression of ventilation, rather than stimulation, in response to hypoxia. In addition, an impaired increase in ventilation, in response to hypercapnia, leads to unstable breathing. This inappropriate response to hypercapnia results from the narrow range between apneic and eupneic $\mathrm{CO}_{2}$ thresholds typical of newborns. ${ }^{11}$

Finally, carotid body responses are related to AOP in preterm infants. The carotid body is a cluster of cells located at the bifurcation of internal and external carotid arteries, and acting as a sensor of arterial partial $\mathrm{O}_{2}$ and $\mathrm{CO}_{2}$ pressures. It is responsible for the rapid rise in ventilation that occurs in response to hypoxia. ${ }^{12}$ Decreased or increased carotid body sensitivity in response to hypoxia has been described in premature infants. ${ }^{13,14}$ Incomplete developmental synaptogenesis, hyperoxic exposures from mechanical ventilatory support are partly responsible for the risk of reduced carotid body sensitivity, along with the effects of lipopolysaccharide and inflammatory mediators such as tumor necrosis factor $\alpha$, which reduce carotid body sensitivity even further. ${ }^{15}$ Moreover, carotid body output and respiratory drive are partly modulated centrally through inhibitory adenosine receptors in the brain stem. Accordingly, methylxanthines, blockers of adenosine A2 receptors, are used to stimulate breathing in infants with AOP. For a more extensive summary on the development of ventilatory control in infants, we refer the reader to an excellent review. ${ }^{10}$

\section{Inflammation}

Systemic inflammation has been implicated in AOP, as it is most evident in infants with sepsis, in whom increased apnea frequency may be the presenting sign of infection.
Apart from the effect of inflammation on the carotid body, described above, systemic or lung inflammation may induce increases in inflammatory mediator levels in the brain stem, which directly inhibit respiratory output signals. ${ }^{11}$

\section{Mechanical Obstruction}

Neonates and young infants are obligatory nasal breathers as a result of their inability to switch from nasal to oral breathing. Thus, when the nasal airway is blocked by secretions or nasal prongs, the premature infant is less likely to bypass the obstruction and mouth breathe. Moreover, several factors further aggravate the physical nasal obstruction. Decreased airway tone in premature infants leads to increased collapsibility. Long-term invasive ventilation promotes the development of airway lesions such as tracheomalacia, bronchomalacia, and subglottic stenosis. In the already pliable airway, characteristic of premature infants, these lesions further predispose them to airway obstruction. ${ }^{16}$

Finally, as further described below, the pronounced laryngeal chemoreflex in premature infants leads to a more prolonged upper airway obstruction secondary to acidic reflux or laryngeal stimulation.

\section{Gastroesophageal Reflux Disorder and Apnea of Prematurity}

Apnea of prematurity and gastroesophageal reflux disorder (GERD) frequently occur in premature infants and often coincide. In the laryngeal chemoreflex, acid reflux irritation leads to laryngeal closure and/or bradycardia. This sequence of events has been documented in humans, as well as in other mammals, ${ }^{17,18}$ and is more pronounced in preterm infants. ${ }^{19}$ Evidence of this reflex was behind the widespread use of antireflux treatments such as formula thickening and medications aimed at preventing laryngeal acid exposures. However, several studies, overall refuting the causal or temporal association between acidic or non-acidic reflux, and the occurrence of apnea in the majority of premature infants, have appeared in recent years. Indeed, Corvaglia et $\mathrm{al}^{20}$ recorded esophageal $\mathrm{pH}$, multiple intraluminal impedance (MII), and cardiorespiratory parameters in 24 infants with AOP who were alternately given thickened or nonthickened formula feedings. Despite a decrease in acidic events as detected in the esophagus, apnea incidence was unchanged in either group. Harris et al $^{21}$ studied 102 slightly older infants with a combination of $\mathrm{pH}$ monitoring and cardiorespiratory recordings. Almost half of the parents reported regurgitation after feeding. However, a definitive temporal relationship between apnea and GER was only shown in one of these infants. Similarly, Di Fiore et $\mathrm{a}^{22}$ studied 119 infants with cardiorespiratory monitoring and esophageal $\mathrm{pH}$ measurements, and found no evidence of a temporal relationship between aciddetected GER and apnea. Moreover, GER events did not prolong the subsequent apnea duration or exacerbate the severity of bradycardia or hypoxemia. A recent study by Rossor et $\mathrm{al}^{23}$ studied 40 premature infants (mean gestational age of 29 weeks) at 37 (30-54) weeks postconceptual age with simultaneous MII, PH-metry, and polysomnography (PSG). Predictably, GER episodes and apnea were more frequent in younger 
infants; however, no temporal relationships (defined as a 5 minutes time window) were observed. Evidence to the contrary is scarce-in a small retrospective study of transpyloric feeding, apnea occurrence was reduced in 12 of 15 infants, ${ }^{24}$ an approach obviously not relevant to the majority of patients with AOP. Taken together, these data suggest that although AOP and GERD often cooccur, there is no evidencebasis for the common practice of anti-reflux therapy to treat AOP, particularly considering that this pharmacotherapy has been shown to cause gut microbiota dysbiosis and increase the risk of NEC. ${ }^{25}$

\section{Genetics}

Although gestational and postconceptual age are the major key players in AOP, several studies have found evidence to support a genetic basis for a proportion of the risk. Bloch-Salisbury et $\mathrm{al}^{26}$ retrospectively studied 317 pairs of premature twins. Heritability, defined as concordance in the diagnosis of AOP between twins, was found in $87 \%$ of same gender monozygotic twins. Genetic factors accounted for $99 \%$ of the variance in AOP diagnosis in male, and $78 \%$ in female, monozygotic twins. In another study, records of 597 premature infants were reviewed, 66 of which had AOP. ${ }^{27}$ First-degree cousin consanguinity was associated with an odds ratio (OR) of 2.89 (1.30-6.43) for AOP. The risk almost doubled in multiple gestation pregnancies $(\mathrm{OR}=4.41 ; 1.38-14.05)$, and was less pronounced in single gestations ( $\mathrm{OR}=1.91 ; 0.61-6.01)$.

Mechanistic evidence to support the genetic basis of AOP can be found in a hypothesis-driven study examining the association of specific, preselected adenosine receptor polymorphisms, and caffeine responsiveness in AOP. ${ }^{28}$ The study found that in cord blood of infants born after 28 weeks of completed gestation, polymorphisms of the A2A adenosine receptor predicted a proportion of the risk development of AOP and response to caffeine therapy.

In addition to genetic risk factors, epigenetic changes, that is, heritable changes in gene expression not involving changes in the DNA, have been implicated in the regulation of neonatal hypoxic responses. In one study, rodents exposed to intermittent hypoxia $(\mathrm{IH})$ in the neonatal period had reduced expression of the antioxidant SOD2 gene in the carotid body, mediated by hypermethylation of said gene. ${ }^{29}$ The authors suggested this mechanism was responsible for the increased hypoxic oxidative stress and abnormal response to IH seen in neonates. Furthermore, the study showed that neonatal exposure to IH, such as that occurs in AOP, predisposes to impaired hypoxia sensing in adulthood. No study to date has examined the epigenetic changes associated with AOP in premature human infants, though epigenetic regulation is central to the pathophysiology of prematurity. ${ }^{30}$

\section{Treatment of Apnea of Prematurity}

Prior to discussing pharmacological interventions, several other measures used to prevent AOP should be addressed:

- Noninvasive respiratory support: Stenting of collapsible airways by positive pressure with noninvasive ventilation is well-established as a method to reduce airway obstruction, leading to improved oxygenation, a reduction in apneic events and increased successful extubation rates. Several methods are used including noninvasive positive pressure ventilation (NIPPV), nasal continuous positive airway pressure (CPAP), and high-flow nasal cannula. All these approaches improve oxygenation by reducing ventilation-perfusion mismatch and work of breathing, and are effective in treating AOP. ${ }^{31-35}$ Recently, a novel flowsynchronized NIPPV method has been suggested as more effective than conventional NIPPV or CPAP for premature infants with AOP. ${ }^{36}$ The different devices/methods have specific advantages and disadvantages that are beyond the scope of this review.

- Prone positioning helps maintain airway patency and avoids over-flexion or extension of the neck, thus preventing obstructive AOP. ${ }^{37}$ Obviously, this is not recommended outside of the monitored neonatal intensive care unit (NICU) environment due to the risk of sudden infant death syndrome (SIDS). ${ }^{38}$

- Stable temperature and avoidance of overheating. High ambient temperature has been shown to reduce ventilation and blunt the normal response to hypoxia ${ }^{39}$ and is associated with SIDS. ${ }^{40}$

- Maintaining $\mathrm{SpO}_{2}$ in the range of 88 to $94 \%$ provides a delicate balance between reducing hypoxia-induced apnea on one hand and decreasing the risk of retinopathy of prematurity on the other. This is an area of much controversy and of ongoing research. ${ }^{41,42}$

- Premature infants with AOP and without continuous hypoxemia can also benefit from low flow supplemental oxygen, as it can stabilize breathing and reduce apnea, bradycardia, and periodic breathing. ${ }^{43,44}$

- Several other nonpharmacological approaches have been tested, albeit with mixed results. These include physical stimulation, ${ }^{45,46}$ olfactory stimulation, ${ }^{47}$ and sound stimulation using maternal sounds. ${ }^{48}$ Other interventions such as increased low dose inspired $\mathrm{CO}_{2}{ }^{49}$ and red blood cell transfusions ${ }^{50,51}$ have been suggested for AOP, though current evidence does not support their routine use.

\section{Pharmacological Interventions}

Methylxanthines

Methylxanthines have been used in the field of neonatology for over 40 years, and are the cornerstone of pharmacologic AOP treatment. Methylxanthines stimulate the medullary respiratory centers through antagonism of adenosine A1 and A2A receptors, both centrally and in the periphery. The downstream effects of the stimulation are increased $\mathrm{CO}_{2}$ and $\mathrm{O}_{2}$ sensing, improved diaphragmatic function and bronchodilation. Taken together, the net effect is an increase in minute ventilation, mostly through the reduction in apneic events in response to hypoxia and an increase in the respiratory drive. ${ }^{52-55}$

Traditionally, theophylline and aminophylline were used to treat apneic premature infants. Over the last two decades, caffeine has gained popularity due to its wider therapeutic window and better safety profile as compared with other 
methylxanthines. ${ }^{56,57}$ Methylxanthines have several side effects including tachycardia, food intolerance, increased metabolic rate, increased $\mathrm{O}_{2}$ consumption, and rarely seizures, all of which are uncommon with standard doses of caffeine. ${ }^{58}$ Consequently, caffeine has become one of the most prescribed and cost-effective treatments in the NICU. ${ }^{59,60}$

With the improved survival of smaller premature infants, concerns were raised as to the safety of caffeine in very low birth weight (VLBW) infants. The caffeine for apnea of prematurity (CAP) trial was established in 2006 to address the safety and efficacy of caffeine in the treatment of infants weighing 500 to $1,250 \mathrm{~g}$, VLBW infants that suffer almost universally from AOP. ${ }^{61}$ This multicenter, randomized, placebo-controlled trial provided evidence for both immediate and long-term follow-up data in this group. The main outcome consisted of a reduction in the rate of bronchopulmonary dysplasia (BPD). In addition, infants in the treatment group had improved survival without neurodevelopmental disability at 18 to 21 months. $^{62}$ Follow-up studies have shown reduced motor impairments, with improved visuomotor, visuoperceptual, and visuospatial abilities at 11 years of age. ${ }^{63,64}$ Importantly, no adverse immediate or long-term effects of caffeine were found and a 2010 Cochrane review concluded that caffeine, as compared with other methylxanthines, was preferable due to its better safety profile. ${ }^{65}$ Cumulatively, these studies have led to a dramatic rise in the use of CAP from $26 \%$ in 1997 to $96 \%$ in $2010 .^{59}$

Caffeine may not only treat established AOP but also prevent its development. Earlier caffeine administration, in the first 3 days of life, has been associated with reduced risk of $\mathrm{BPD},{ }^{66}$ though there is insufficient evidence to support routine caffeine prophylaxis in the first days of life for all premature infants. $^{67,68}$

Several questions raised in recent years remain unanswered. One such question is the optimal dose of CAP. The original loading dose of $20 \mathrm{mg} / \mathrm{kg}$ used in the CAP trial is still the norm, though studies have suggested that a higher loading and maintenance doses may provide an additional benefit in terms of apnea reduction, with no adverse effect on the safety profile. ${ }^{69,70}$ Finally, the timing of caffeine cessation is a difficult decision, and it has been suggested that the standard cut-off of 34 wGA may not be sufficient to protect infants from continued $\mathrm{IH}$. Rhein and colleagues examined 95 infants born $<32 \mathrm{wGA}$, and found that substantial IH persisted after discontinuation of routine caffeine treatment at $34 \mathrm{wGA}$, and progressively decreased with increasing postmenstrual age (PMA). Extending caffeine treatment up to $40 \mathrm{wGA}$ decreased $\mathrm{IH}$ in premature infants; ${ }^{71,72}$ however, it is not known whether this reduction has any positive long-term effects.

\section{Doxapram}

Doxapram is a respiratory neurostimulant that increases ventilation. The immediate target of doxapram is unclear, acting either directly on central chemoreceptors or through sensitization of peripheral receptors to hypoxemia. ${ }^{73}$ Compared with methylxanthines, doxapram does not improve diaphragmatic function. ${ }^{74}$ Adverse effects of high-dose doxapram include cardiac conduction disorders ${ }^{75}$ and gastrointestinal perfora- tion and NEC, ${ }^{76}$ all of which are far less common with low-dose doxapram. ${ }^{77}$ In premature infants, doxapram has mainly been used as a second-line therapy after caffeine failure. Such infants on doxapram have a priori more unstable respiration and are more vulnerable to the detrimental effects of hypoxemia. Accordingly, though cumulative evidence supports the ability of doxapram to treat apnea, the long-term consequences are unclear. Yamazaki et $\mathrm{al}^{78}$ prospectively studied 106 VLBW infants with AOP, comparing standalone methylxanthine treatment with doxapram in addition to methylxanthine. They found an $80 \%$ success rate in reducing apnea frequency, and significantly reduced death rates in doxapram-treated infants. In a retrospective cohort study, Ten Hove et $\mathrm{al}^{79}$ demonstrated lower mortality rates and neurodevelopmental disability at 24 months in 142 premature infants $<30$ wGA and $<1250 \mathrm{~g}$ treated with doxapram on top of caffeine, as compared with the 284 infants treated with caffeine alone. However, the doxapram-exposed group in this study had more BPD and patent ductus arteriosus (PDA). In summary, it appears that doxapram therapy is beneficial in infants with persistent AOP despite caffeine and optimal care, but randomized controlled trials are lacking, and the late outcomes of premature infants treated with doxapram for AOP are unclear. ${ }^{77,79-81}$

\section{Novel Therapies}

Research continues for novel pharmacological interventions for those infants with AOP that do not respond to methylxanthines. One such example is an ampakine compound CX1739, a positive allosteric modulator of amino-3-hydroxy5-methyl-4-isoxazolepropionate receptors. A recent study by Ren et $\mathrm{al}^{82}$ demonstrated that CX1739 increases respiratory drive, and reduces apneas both under normoxia and hypoxia in a perinatal rat model. No clinical trial to date has tested this drug to prevent AOP in human infants.

\section{Discharge Considerations}

Polysomnography in the Neonatal Intensive Care Unit The PSG is the gold standard for the evaluation of sleepdisordered breathing in children, but is relatively expensive, time consuming, and not consistently used or available. ${ }^{83,84} \mathrm{~A}$ full, type 1 PSG, includes monitoring of electroencephalogram, electrooculogram, chin electromyography, airflow, arterial oxygen saturation, respiratory effort, and heart rate or electrocardiogram channel and according to the indication carbon dioxide as well as video and audio recording. ${ }^{85}$ There are no formal guidelines on the need for a PSG on discharge from the NICU. However, it has been noted that a PSG may play a role in identifying those infants at risk of sleep-related breathing events and be useful in guiding physicians during discharge planning. ${ }^{86}$ Criteria for NICU discharge include maturity of cardiorespiratory function, but there are no clear definitions on what constitutes maturity or how it should be assessed. ${ }^{87}$ In 2011 to 2012, the American Academy of Sleep Medicine published practice parameters for the respiratory and nonrespiratory indications for PSG in children. ${ }^{84,88}$ It was noted that a PSG is indicated when congenital central alveolar hypoventilation syndrome, hypoventilation due to a 
neuromuscular disorders, or chest wall deformities are suspected, as well as in selected cases of primary sleep apnea of infancy. However, it was also noted that a PSG is often not available in this setting (the NICU).

There are only limited large-scale studies of PSGs in premature infants prior to discharge. Daniels et al suggested a possible role for PSGs in predicting life threatening events. Of 1,274 premature infants studied prior to discharge, none of those infants with normal studies had life-threatening events thereafter, albeit, these infants were not discharged with monitoring devices. ${ }^{89}$ Naulaers et al studied a total of 1,058 infants prior to discharge. ${ }^{90}$ PSG findings led to a recommendation for home monitoring in 96 infants, 17 of whom had serious alarms. However, pneumograms in the NICU were chosen in the 2015 American Academy of Pediatrics (AAP) "Choosing Wisely" campaign survey, as one of five tests (out of 1,648 candidate tests) that were unnecessary, except in selected cases in which the etiology of cardiorespiratory events was in doubt. ${ }^{91}$ Osman et al performed a retrospective study of PSGs performed in a tertiary center NICU to assess their impact on management and outcomes. ${ }^{87}$ A total of 110 infants were studied at an average age of $36.9 \pm 2.5$ weeks PMA. Results were abnormal in $95 \%$, and the majority of infants was discharged home on a cardiorespiratory monitor. Of the studied infants, 11 were readmitted for apparent life-threatening events, but there was no association between PSG results and readmission. In summary, it would seem that the routine use of full PSG for decision discharge is unnecessary and not cost-effective; however, this tool should be kept in mind for infants with unusually severe presentation of apnea or when other conditions may be present (e.g., suspected seizures).

Possible options exist as surrogates or alternatives to full PSGs in the NICU. One such option is a nap study-usually performed between feeds with a target sleep of at least 2 hours; however, studies have also explored simpler methods such as oximetry recordings and shown promising results, ${ }^{92}$ with some authors advocating their use as an initial screening tool. ${ }^{93}$ While such a study documents the oximetry levels and may help determine the need for ongoing oxygen supplementation, it is obviously incapable of identification of obstructive sleep apnea.

\section{Home Apnea Monitoring}

Home monitors are widely used as a means to detect abnormal heart and breathing in newborns at home, and are often prescribed by physicians during discharge from the NICU. Monitors were originally prescribed to prevent SIDS, based on the hypothesis that the latter was caused by prolonged apneas. However, this hypothesis was never proven and no prospective data showed an effect on sudden unexpected infant death (SUID) rates, leading to the $\mathrm{AAP}^{94}$ recommendation against their routine use. ${ }^{95}$ The Collaborative Home Infant Monitoring Evaluation Study showed that preterm infants had more events than SIDS siblings, infants that had experienced an apparent life threatening event (ALTE) event or healthy infants. "Extreme events" (apnea $>30$ seconds and/or heart rate 10 seconds) were common in preterm infants but very rare after
43 weeks postconceptual age. ${ }^{96}$ Thus, while routine monitoring is not recommended, it is often considered in cases with a prolonged course of recurrent, extreme apnea, in which case it can usually be discontinued after 43 weeks. ${ }^{6}$ There are several possible additional benefits to their use. Monitors may play a role in curtailing long events, thereby mitigating the effects of prolonged hypoxic events. They may serve as a diagnostic tool with careful review of downloads suggesting such diagnoses as gastroesophageal reflux, arrhythmias, and seizures, and it has been suggested that an increase in alarms may be an early sign of an respiratory syncytial virus (RSV) infection. ${ }^{95}$ Apnea monitors have the potential of being cost-effective devices, enabling early NICU discharge, reducing family costs, and decreasing time off from work. A recent study by Montenegro et al showed that a hypothetical outpatient management plan could lead to $\$ 2,422$ to $\$ 62$ being saved per eligible patient. ${ }^{97}$ Furthermore, the psychological benefit should be considered with better parental emotional well-being and quality of home life following early discharge. ${ }^{98}$ Premature infants are at increased risk of apnea following routine immunization, and home apnea monitoring may be useful in this context as well, at least for a short period of time. ${ }^{99}$

\section{Prognosis}

\section{Neurodevelopmental Disability}

The largest study to date to examine the association of neurodevelopmental outcomes with $\mathrm{IH}$ or bradycardias in premature infants was performed by the Canadian Oxygen Trial network of 25 hospitals in Canada, United States, Israel, Germany, Finland, and Argentina. ${ }^{100}$ In a posthoc analysis of the original study, primarily aimed at defining the desirable therapeutic oxygen target, hypoxemia (oxygen saturation $<80 \%$ ) and bradycardia (heart rate $<80 / \mathrm{min}$ ) events, lasting 10 seconds or longer, in the first 3 months of life, in extremely premature infants (born 23-28 wGA), were documented. The major finding of this study was an increased risk for late death or disability by 18 months of corrected age, as a function of the time the premature infants experienced hypoxemia. The study showed a relative risk of 1.53 for highest versus lowest decile of time spent with hypoxemia. Secondary outcomes including motor impairments, cognitive or speech delays, and severe retinopathy of prematurity showed similar associations with time spent with hypoxemia. The longest events (lasting over 1 minute) conferred the highest risk for adverse outcomes. Bradycardia events did not add to the predictive value of hypoxemia. As noted earlier, caffeine has a strong protective effect on infants with AOP-in the CAP trial, caffeine had significantly improved neurodevelopmental outcomes at 18 to 24 months of age, and reduced the risk of neurodevelopmental disability, cerebral palsy, and cognitive delay. ${ }^{62}$ When measured at the age of 5 years, the protective effect of caffeine seemed to disappear. Neonatal caffeine therapy was no longer associated with a significantly improved rate of survival without disability in children with VLBWs. ${ }^{101}$ However, at the age of 11 years, caffeine therapy showed some long-lasting effects. Former VLBW infants who had received CAP had a reduced risk of motor impairments and improved visual abilities. ${ }^{64,102}$ 


\section{Sudden Infant Death}

Premature infants are at increased risk of SIDS and SUID. With each week of earlier gestational age, the risk rises incrementally, with the infants born the youngest having the highest risk. ${ }^{103}$ Since the youngest premature infants are also prone to AOP, an association between SIDS and AOP could be expected. Several authors have suggested the link to be through impaired arousability from sleep. Decreased arousability is central to the pathogenesis of SIDS, ${ }^{38,104}$ and infants with a history of AOP may have similar features. One study examined 25 premature infants, 15 of which had a history of AOP. ${ }^{105}$ The infants were studied at $36 \mathrm{WGA}$, within 3 weeks of term and 2 to 3 months thereafter. Arousal threshold, as measured by stimulation to the nostrils by air-jets of increasing pressures, was elevated at all time points in infants with a history of AOP, indicating less arousability from sleep in this group. A significant limitation to the study was the younger gestational age at birth of the apneic group as compared with the control group (28.6 vs. 33.4 weeks) which could have accounted for the differential responses. Despite the biological plausibility, epidemiological data do not support an association between AOP and subsequent SIDS. In one of the earliest studies, Southall et a $1^{106}$ examined outcomes of 1,157 infants with cardiorespiratory recordings on discharge from the NICU. Five infants subsequently died with a diagnosis of SIDS, and no association was observed between apnea and risk of SIDS. A large-scale study published in 1988 and summarizing data from 10 centers across the United States concluded that AOP was not independently associated with an increased risk of SIDS, when age and low-birth weight were included in the statistical analyses as confounders. ${ }^{40}$ However, as mentioned earlier, some evidence does support the notion that at least in the extremely premature infants IH early in life is associated with later death. ${ }^{100}$

\section{Follow-Up Recommendations}

As AOP can persist beyond discharge or 43 weeks PMA or reoccur in some infants, the AAP recommends close followup and monitoring in conditions of increased stress, including viral infections, general anesthesia, or immunization. ${ }^{6}$

We would recommend the following protocol for premature infants with a history of significant AOP and especially those diagnosed with BPD:

- Pulmonary follow-up at 2 to 3 months post-discharge and at least one additional visit 3 months thereafter. At these visits, beyond the routine pulmonary assessment, attention should be paid to the subtle signs of $I H$ in sleep in those children. Those include poor growth, feeding difficulties, restless sleep, and frequent alarms if the child is monitored.

- For children discharged with supplemental oxygen therapy, daytime oxygen can be weaned off if no clinical signs of increased work of breathing or growth delay are apparent and oxygen saturation is consistently above 94 to $95 \%{ }^{107}$
- Clinically silent OSA is frequently encountered in VLBW infants, especially those with a history of BPD, ${ }^{108-110}$ and we thus recommend using PSG to decide whether to wean from oxygen at night. PSG may prove useful in detecting residual $\mathrm{AOP} / \mathrm{sleep}$ apnea in these infants and guide treatment, whether supplemental oxygen, positive pressure ventilatory support, or surgery.

In summary, it is clear that AOP, and specifically the accompanying $\mathrm{IH}$, is associated with an increased risk of death and developmental disability, more so in extremely premature infants. Furthermore, it is clear that caffeine may negate the short-term effects of AOP, and possibly also attenuate the long-term effects. Premature infants are at increased risk of cardiometabolic morbidity later in life, such as obesity, hypertension, and metabolic syndrome. Whether AOP, and the ensuing $\mathrm{IH}$, predisposes former premature infants to unstable breathing later in life or to other prematurity-related morbidity remains unclear.

Conflict of Interest

None declared.

\section{References}

1 Harrison MS, Goldenberg RL. Global burden of prematurity. Semin Fetal Neonatal Med 2016;21(02):74-79

2 Bolton CE, Bush A, Hurst JR, Kotecha S, McGarvey L. Lung consequences in adults born prematurely. Thorax 2015;70(06):574-580

3 Sullivan MC, Winchester SB, Msall ME. Prematurity and cardiovascular risk at early adulthood. Child Care Health Dev 2019;45 (01):71-78

4 Allotey J, Zamora J, Cheong-See F, et al. Cognitive, motor, behavioural and academic performances of children born preterm: a meta-analysis and systematic review involving 64061 children. BJOG 2018;125(01):16-25

5 Henderson-Smart DJ, Cohen G. Apnoea in the newborn infant. Aust Paediatr J 1986;22(Suppl 1):63-66

6 Eichenwald EC. Committee on Fetus and Newborn, American Academy of Pediatrics. Apnea of prematurity. Pediatrics 2016;137(1)

7 Kesavan K, Parga J. Apnea of prematurity: current practices and future directions. Neoreviews 2017;18(03):e149-e160

8 Feldman JL, Mitchell GS, Nattie EE. Breathing: rhythmicity, plasticity, chemosensitivity. Annu Rev Neurosci 2003;26:239-266

9 Henderson-Smart DJ, Pettigrew AG, Campbell DJ. Clinical apnea and brain-stem neural function in preterm infants. $\mathrm{N}$ Engl J Med 1983;308(07):353-357

10 Carroll JL, Agarwal A. Development of ventilatory control in infants. Paediatr Respir Rev 2010;11(04):199-207

11 Di Fiore JM, Martin RJ, Gauda EB. Apnea of prematurity-perfect storm. Respir Physiol Neurobiol 2013;189(02):213-222

12 Kumar P, Prabhakar NR. Peripheral chemoreceptors: function and plasticity of the carotid body. Compr Physiol 2012;2(01):141-219

13 Prabhakar NR, Peng YJ, Kumar GK, Pawar A. Altered carotid body function by intermittent hypoxia in neonates and adults: relevance to recurrent apneas. Respir Physiol Neurobiol 2007;157 (01):148-153

14 Donnelly DF. Developmental aspects of oxygen sensing by the carotid body. J Appl Physiol (1985) 2000;88(06):2296-2301

15 Gauda EB, Shirahata M, Mason A, Pichard LE, Kostuk EW, ChavezValdez R. Inflammation in the carotid body during development and its contribution to apnea of prematurity. Respir Physiol Neurobiol 2013;185(01):120-131 
16 Idiong N, Lemke RP, Lin YJ, Kwiatkowski K, Cates DB, Rigatto H. Airway closure during mixed apneas in preterm infants: is respiratory effort necessary? J Pediatr 1998;133(04):509-512

17 Davies AM, Koenig JS, Thach BT. Upper airway chemoreflex responses to saline and water in preterm infants. J Appl Physiol (1985) 1988;64(04):1412-1420

18 Boggs DF, Bartlett D Jr. Chemical specificity of a laryngeal apneic reflex in puppies. J Appl Physiol 1982;53(02):455-462

19 Pickens DL, Schefft G, Thach BT. Prolonged apnea associated with upper airway protective reflexes in apnea of prematurity. Am Rev Respir Dis 1988;137(01):113-118

20 Corvaglia L, Spizzichino M, Aceti A, et al. A thickened formula does not reduce apneas related to gastroesophageal reflux in preterm infants. Neonatology 2013;103(02):98-102

21 Harris P, Muñoz C, Mobarec S, Brockmann P, Mesa T, Sánchez I. Relevance of the $\mathrm{pH}$ probe in sleep study analysis in infants. Child Care Health Dev 2004;30(04):337-344

22 Di Fiore JM, Arko M, Whitehouse M, Kimball A, Martin RJ. Apnea is not prolonged by acid gastroesophageal reflux in preterm infants. Pediatrics 2005;116(05):1059-1063

23 Rossor T, Andradi G, Ali K, Bhat R, Greenough A. Gastro-oesophageal reflux and apnoea: is there a temporal relationship? Neonatology 2018;113(03):206-211

24 Misra S, Macwan K, Albert V. Transpyloric feeding in gastroesophageal-reflux-associated apnea in premature infants. Acta Paediatr 2007;96(10):1426-1429

25 Corvaglia L, Monari C, Martini S, Aceti A, Faldella G. Pharmacological therapy of gastroesophageal reflux in preterm infants. Gastroenterol Res Pract 2013;2013:714564

26 Bloch-Salisbury E, Hall MH, Sharma P, Boyd T, Bednarek F, Paydarfar D. Heritability of apnea of prematurity: a retrospective twin study. Pediatrics 2010;126(04):e779-e787

27 Tamim H, Khogali M, Beydoun H, Melki I, Yunis K; National Collaborative Perinatal Neonatal Network. Consanguinity and apnea of prematurity. Am J Epidemiol 2003;158(10):942-946

28 Kumral A, Tuzun F, Yesilirmak DC, Duman N, Ozkan H. Genetic basis of apnoea of prematurity and caffeine treatment response: role of adenosine receptor polymorphisms: genetic basis of apnoea of prematurity. Acta Paediatr 2012;101(07):e299-e303

29 Nanduri J, Makarenko V, Reddy VD, et al. Epigenetic regulation of hypoxic sensing disrupts cardiorespiratory homeostasis. Proc Natl Acad Sci U S A 2012;109(07):2515-2520

30 Ribeiro de Andrade Ramos B, da Silva MG. The burden of genetic and epigenetic traits in prematurity. Reprod Sci 2018;25(04): 471-479

31 Lemyre B, Davis PG, De Paoli AG, Kirpalani H. Nasal intermittent positive pressure ventilation (NIPPV) versus nasal continuous positive airway pressure (NCPAP) for preterm neonates after extubation. Cochrane Database Syst Rev 2017;2:CD003212

32 Sreenan C, Lemke RP, Hudson-Mason A, Osiovich H. High-flow nasal cannulae in the management of apnea of prematurity: a comparison with conventional nasal continuous positive airway pressure. Pediatrics 2001;107(05):1081-1083

33 Al-Alaiyan S, Dawoud M, Al-Hazzani F. Positive distending pressure produced by heated, humidified high flow nasal cannula as compared to nasal continuous positive airway pressure in premature infants. J Neonatal Perinatal Med 2014;7(02):119-124

34 Yoder BA, Stoddard RA, Li M, King J, Dirnberger DR, Abbasi S. Heated, humidified high-flow nasal cannula versus nasal CPAP for respiratory support in neonates. Pediatrics 2013;131(05): e1482-e1490

35 Ciuffini F, Pietrasanta C, Lavizzari A, et al. Comparison between two different modes of non-invasive ventilatory support in preterm newborn infants with respiratory distress syndrome mild to moderate: preliminary data. Pediatr Med Chir 2014;36 (04):88

36 Gizzi C, Montecchia F, Panetta V, et al. Is synchronised NIPPV more effective than NIPPV and NCPAP in treating apnoea of prematurity (AOP)? A randomised cross-over trial. Arch Dis Child Fetal Neonatal Ed 2015;100(01):F17-F23

37 Kurlak LO, Ruggins NR, Stephenson TJ. Effect of nursing position on incidence, type, and duration of clinically significant apnoea in preterm infants. Arch Dis Child Fetal Neonatal Ed 1994;71(01): F16-F19

38 Kinney HC, Thach BT. The sudden infant death syndrome. N Engl J Med 2009;361(08):795-805

39 McDonald FB, Chandrasekharan K, Wilson RJ, Hasan SU. Interactive effects of maternal cigarette smoke, heat stress, hypoxia, and lipopolysaccharide on neonatal cardiorespiratory and cytokine responses. Am J Physiol Regul Integr Comp Physiol 2016; 311(06):R1113-R1124

40 Hoffman HJ, Damus K, Hillman L, Krongrad E. Risk factors for SIDS. Results of the National Institute of Child Health and Human Development SIDS Cooperative Epidemiological Study. Ann N Y Acad Sci 1988;533:13-30

41 Manja V, Lakshminrusimha S, Cook DJ. Oxygen saturation target range for extremely preterm infants: a systematic review and meta-analysis. JAMA Pediatr 2015;169(04):332-340

42 Raffay TM, Walsh MC. Pulse oximetry targets in extremely premature infants and associated mortality: one-size may not fit all. J Nat Sci 2018;4(06):e508

43 Simakajornboon N, Beckerman RC, Mack C, Sharon D, Gozal D. Effect of supplemental oxygen on sleep architecture and cardiorespiratory events in preterm infants. Pediatrics 2002;110(05): 884-888

44 Seppä-Moilanen M, Andersson S, Rantakari K, Mikkola K, Kirjavainen T. Caffeine and supplemental oxygen effectively suppress periodic breathing with only minor effects during long episodes of apnoea in preterm infants. Acta Paediatr 2018

45 Kesavan K, Frank P, Cordero DM, Benharash P, Harper RM. Neuromodulation of limb proprioceptive afferents decreases apnea of prematurity and accompanying intermittent hypoxia and bradycardia. PLoS One 2016;11(06):e0157349

46 Henderson-Smart DJ, Osborn DA. Kinesthetic stimulation for preventing apnea in preterm infants. Cochrane Database Syst Rev 2002;(02):CD000373

47 Marlier L, Gaugler C, Messer J. Olfactory stimulation prevents apnea in premature newborns. Pediatrics 2005;115(01):83-88

48 Doheny L, Hurwitz S, Insoft R, Ringer S, Lahav A. Exposure to biological maternal sounds improves cardiorespiratory regulation in extremely preterm infants. J Matern Fetal Neonatal Med 2012;25(09):1591-1594

49 Alvaro RE, Khalil M, Qurashi M, et al. $\mathrm{CO}(2)$ inhalation as a treatment for apnea of prematurity: a randomized double-blind controlled trial. J Pediatr 2012;160(02):252-257.e1

50 Whyte R, Kirpalani H. Low versus high haemoglobin concentration threshold for blood transfusion for preventing morbidity and mortality in very low birth weight infants. Cochrane Database Syst Rev 2011;(11):CD000512

51 Bell EF, Strauss RG, Widness JA, et al. Randomized trial of liberal versus restrictive guidelines for red blood cell transfusion in preterm infants. Pediatrics 2005;115(06):1685-1691

52 Rigatto H, Desai U, Leahy F, Kalapesi Z, Cates D. The effect of $2 \%$ CO2, $100 \%$ O2, theophylline and 15\% O2 on "inspiratory drive" and "effective" timing in preterm infants. Early Hum Dev 1981;5 (01):63-70

53 Bhatt-Mehta V, Schumacher RE. Treatment of apnea of prematurity. Paediatr Drugs 2003;5(03):195-210

54 Dobson NR, Hunt CE. Pharmacology review: caffeine use in neonates: indications, pharmacokinetics, clinical effects, outcomes. Neoreviews 2013;14(11):e540

55 Parikka V, Beck J, Zhai Q Leppäsalo J, Lehtonen L, Soukka H. The effect of caffeine citrate on neural breathing pattern in preterm infants. Early Hum Dev 2015;91(10):565-568

56 Dobson NR, Hunt CE. Caffeine: an evidence-based success story in VLBW pharmacotherapy. Pediatr Res 2018;84(03):333-340 
57 Spitzer AR. Evidence-based methylxanthine use in the NICU. Clin Perinatol 2012;39(01):137-148

58 Abu-Shaweesh JM, Martin RJ. Neonatal apnea: what's new? Pediatr Pulmonol 2008;43(10):937-944

59 Dobson NR, Patel RM, Smith PB, et al. Trends in caffeine use and association between clinical outcomes and timing of therapy in very low birth weight infants. J Pediatr 2014;164(05):992-998.e3

60 Kreutzer K, Bassler D. Caffeine for apnea of prematurity: a neonatal success story. Neonatology 2014;105(04):332-336

61 Schmidt B, Roberts RS, Davis P, et al; Caffeine for Apnea of Prematurity Trial Group. Caffeine therapy for apnea of prematurity. N Engl J Med 2006;354(20):2112-2121

62 Schmidt B, Roberts RS, Davis P, et al; Caffeine for Apnea of Prematurity Trial Group. Long-term effects of caffeine therapy for apnea of prematurity. N Engl J Med 2007;357(19):1893-1902

63 Mürner-Lavanchy IM, Doyle LW, Schmidt B, et al; Caffeine for Apnea of Prematurity (CAP) Trial Group. Neurobehavioral outcomes 11 years after neonatal caffeine therapy for apnea of prematurity. Pediatrics 2018;141(05):e20174047

64 Schmidt B, Roberts RS, Anderson PJ, et al; Caffeine for Apnea of Prematurity (CAP) Trial Group. Academic performance, motor function, and behavior 11 years after neonatal caffeine citrate therapy for apnea of prematurity: an 11-year follow-up of the cap randomized clinical trial. JAMA Pediatr 2017;171(06):564-572

65 Henderson-Smart DJ, De Paoli AG. Methylxanthine treatment for apnoea in preterm infants. Cochrane Database Syst Rev 2010; (12):CD000140

66 Lodha A, Seshia M, McMillan DD, et al; Canadian Neonatal Network. Association of early caffeine administration and neonatal outcomes in very preterm neonates. JAMA Pediatr 2015; 169(01):33-38

67 Kua KP, Lee SW. Systematic review and meta-analysis of clinical outcomes of early caffeine therapy in preterm neonates. Br J Clin Pharmacol 2017;83(01):180-191

68 Henderson-Smart DJ, De Paoli AG. Prophylactic methylxanthine for prevention of apnoea in preterm infants. Cochrane Database Syst Rev 2010;(12):CD000432

69 Vliegenthart R, Miedema M, Hutten GJ, van Kaam AH, Onland W. High versus standard dose caffeine for apnoea: a systematic review. Arch Dis Child Fetal Neonatal Ed 2018;103(06):F523-F529

70 Mohammed S, Nour I, Shabaan AE, Shouman B, Abdel-Hady H, Nasef N. High versus low-dose caffeine for apnea of prematurity: a randomized controlled trial. Eur J Pediatr 2015;174(07):949-956

71 Rhein LM, Dobson NR, Darnall RA, et al; Caffeine Pilot Study Group. Effects of caffeine on intermittent hypoxia in infants born prematurely: a randomized clinical trial. JAMA Pediatr 2014;168 (03):250-257

72 Dobson NR, Rhein LM, Darnall RA, et al; Caffeine Study Group. Caffeine decreases intermittent hypoxia in preterm infants nearing term-equivalent age. J Perinatol 2017;37(10):1135-1140

73 Yost CS. A new look at the respiratory stimulant doxapram. CNS Drug Rev 2006;12(3-4):236-249

74 de Waal CG, Hutten GJ, Kraaijenga JV, de Jongh FH, van Kaam AH. Doxapram treatment and diaphragmatic activity in preterm infants. Neonatology 2019;115(01):85-88

75 Miyata M, Hata T, Kato N, et al. Dynamic QT/RR relationship of cardiac conduction in premature infants treated with low-dose doxapram hydrochloride. J Perinat Med 2007;35(04):330-333

76 Tay-Uyboco J, Kwiatkowski K, Cates DB, Seifert B, Hasan SU, Rigatto $\mathrm{H}$. Clinical and physiological responses to prolonged nasogastric administration of doxapram for apnea of prematurity. Biol Neonate 1991;59(04):190-200

77 Vliegenthart RJ, Ten Hove CH, Onland W, van Kaam AH. Doxapram treatment for apnea of prematurity: a systematic review. Neonatology 2017;111(02):162-171

78 Yamazaki T, Kajiwara M, Itahashi K, Fujimura M. Low-dose doxapram therapy for idiopathic apnea of prematurity. Pediatr Int 2001;43(02):124-127
79 Ten Hove $\mathrm{CH}$, Vliegenthart RJ, Te Pas $\mathrm{AB}$, et al. Long-term neurodevelopmental outcome after doxapram for apnea of prematurity. Neonatology 2016;110(01):21-26

80 Flint R, Halbmeijer N, Meesters N, et al. Retrospective study shows that doxapram therapy avoided the need for endotracheal intubation in most premature neonates. Acta Paediatr 2017;106 (05):733-739

81 Prins SA, Pans SJ, van Weissenbruch MM, Walther FJ, Simons SH. Doxapram use for apnoea of prematurity in neonatal intensive care. Int J Pediatr 2013;2013:251047

82 Ren J, Ding X, Greer JJ. Ampakines enhance weak endogenous respiratory drive and alleviate apnea in perinatal rats. Am J Respir Crit Care Med 2015;191(06):704-710

83 Marcus CL, Brooks LJ, Draper KA, et al; American Academy of Pediatrics. Diagnosis and management of childhood obstructive sleep apnea syndrome. Pediatrics 2012;130(03):576-584

84 Aurora RN, Zak RS, Karippot A, et al; American Academy of Sleep Medicine. Practice parameters for the respiratory indications for polysomnography in children. Sleep (Basel) 2011;34(03): 379-388

85 Kushida CA, Littner MR, Morgenthaler T, et al. Practice parameters for the indications for polysomnography and related procedures: an update for 2005. Sleep 2005;28(04):499-521

86 Joosten K, de Goederen R, Pijpers A, Allegaert K. Sleep related breathing disorders and indications for polysomnography in preterm infants. Early Hum Dev 2017;113:114-119

87 Osman AF, Thomas B, Singh N, Collin M, Shekhawat PS. Impact of infant-polysomnography studies on discharge management and outcomes: a 5 year experience from a tertiary care unit. J Neonatal Biol 2017;6(02):257

88 Aurora RN, Lamm CI, Zak RS, et al. Practice parameters for the non-respiratory indications for polysomnography and multiple sleep latency testing for children. Sleep (Basel) 2012;35(11): 1467-1473

89 Daniëls H, Naulaers G, Deroost F, Devlieger H. Polysomnography and home documented monitoring of cardiorespiratory pattern. Arch Dis Child 1999;81(05):434-436

90 Naulaers G, Daniels H, Allegaert K, Rayyan M, Debeer A, Devlieger $\mathrm{H}$. Cardiorespiratory events recorded on home monitors: the effect of prematurity on later serious events. Acta Paediatr 2007; 96(02):195-198

91 HoT, Dukhovny D, Zupancic JA, Goldmann DA, Horbar JD, Pursley DM. Choosing Wisely in Newborn Medicine: Five Opportunities to Increase Value. Pediatrics 2015;136(02):e482-e489

92 Roberts T, Campbell A, Larsen P, Elder D. Preterm infants at discharge: nap polysomnography versus 24 -hour oximetry. Acta Paediatr 2017;106(11):1754-1759

93 Zenteno D, Bancalari A, Navarro X, Díaz V, Rodríguez-Núñez I, Brockmann P. [Diagnosis of respiratory sleep disorders in newborns with suspected apneas: comparison between nocturnal saturometry and polygraphy]. Rev Chil Pediatr 2017;88(06): 759-764

94 Task Force On Sudden Infant Death S. SIDS and Other SleepRelated Infant Deaths. Updated 2016 recommendations for a safe infant sleeping environment. Pediatrics 2016;138(5)

95 Freed GE, Martinez F. The history of home cardiorespiratory monitoring. Pediatr Ann 2017;46(08):e303-e308

96 Ramanathan R, Corwin MJ, Hunt CE, et al; Collaborative Home Infant Monitoring Evaluation (CHIME) Study Group. Cardiorespiratory events recorded on home monitors: Comparison of healthy infants with those at increased risk for SIDS. JAMA 2001; 285(17):2199-2207

97 Montenegro BL, Amberson M, Veit L, Freiberger C, Dukhovny D, Rhein LM. Economics of home monitoring for apnea in late preterm infants. Respir Care 2017;62(01):42-48

98 Jefferies AL; Canadian Paediatric Society, Fetus and Newborn Committee. Going home: facilitating discharge of the preterm infant. Paediatr Child Health 2014;19(01):31-42 
99 Omeñaca F, Vázquez L, Garcia-Corbeira P, et al. Immunization of preterm infants with GSK's hexavalent combined diphtheriatetanus-acellular pertussis-hepatitis B-inactivated poliovirusHaemophilus influenzae type b conjugate vaccine: a review of safety and immunogenicity. Vaccine 2018;36(07):986-996

100 Poets CF, Roberts RS, Schmidt B, et al; Canadian Oxygen Trial Investigators. Association between intermittent hypoxemia or bradycardia and late death or disability in extremely preterm infants. JAMA 2015;314(06):595-603

101 Schmidt B, Anderson PJ, Doyle LW, et al; Caffeine for Apnea of Prematurity (CAP) Trial Investigators. Survival without disability to age 5 years after neonatal caffeine therapy for apnea of prematurity. JAMA 2012;307(03):275-282

102 Atik A, Harding R, De Matteo R, et al. Caffeine for apnea of prematurity: effects on the developing brain. Neurotoxicology 2017;58:94-102

103 Ostfeld BM, Schwartz-Soicher O, Reichman NE, Teitler JO, Hegyi T. Prematurity and sudden unexpected infant deaths in the United States. Pediatrics 2017;140(01):e20163334

104 Tuladhar R, Harding R, Cranage SM, Adamson TM, Horne RS. Effects of sleep position, sleep state and age on heart rate responses following provoked arousal in term infants. Early Hum Dev 2003;71(02):157-169

105 Horne RS, Andrew S, Mitchell K, et al. Apnoea of prematurity and arousal from sleep. Early Hum Dev 2001;61(02):119-133

106 Southall DP, Richards JM, Rhoden KJ, et al. Prolonged apnea and cardiac arrhythmias in infants discharged from neonatal intensive care units: failure to predict an increased risk for sudden infant death syndrome. Pediatrics 1982;70(06): 844-851

107 Rhein L, Simoneau T, Davis J, et al. Reference values of nocturnal oxygenation for use in outpatient oxygen weaning protocols in premature infants. Pediatr Pulmonol 2012;47(05):453-459

108 Ortiz LE, McGrath-Morrow SA, Sterni LM, Collaco JM. Sleep disordered breathing in bronchopulmonary dysplasia. Pediatr Pulmonol 2017;52(12):1583-1591

109 Qubty WF, Mrelashvili A, Kotagal S, Lloyd RM. Comorbidities in infants with obstructive sleep apnea. J Clin Sleep Med 2014;10 (11):1213-1216

110 Sharma PB, Baroody F, Gozal D, Lester LA. Obstructive sleep apnea in the formerly preterm infant: an overlooked diagnosis. Front Neurol 2011;2:73 